\title{
Successful treatment of giant pheochromocytoma-induced Takotsubo syndrome with adrenalectomy
}

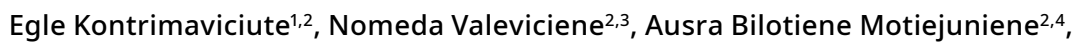 \\ Agne Jankuviene, ${ }^{1,2}$, Ruta Januleviciene ${ }^{1,2}$, Smilte Kolevinskaite ${ }^{1,2}$ \\ 1 Clinic of Anaesthesiology and Intensive Care, Faculty of Medicine, Vilnius University, Vilnius, Lithuania \\ 2 Vilnius University Hospital Santaros Klinikos, Vilnius, Lithuania \\ 3 Department of Radiology, Nuclear Medicine and Medical Physics, Faculty of Medicine, Vilnius University, Vilnius, Lithuania \\ 4 Department of Public Health, Faculty of Medicine, Vilnius University, Vilnius, Lithuania
}

\section{Correspondence to:}

Egle Kontrimaviciute, MD, PhD, Vilnius University Hospital Santaros Klinikos, Santariskiu 2, Vilnius, Lithuania, phone: +37052365264, email: egle.kontrimaviciute@santa.lt Received: September 18, 2019. Revision accepted: December 30, 2019. Published online: January 4, 2020. Kardiol Pol. 2020; 78 (3): 249-250 doi:10.33963/KP.15122 Copyright by the Author(s), 2020
A hypertensive crisis or an acute increase in diastolic blood pressure $(>120 \mathrm{~mm} \mathrm{Hg})$ in middle-aged adults with symptoms of palpitation, flushing, sweating, and syncope may suggest renal or endocrine disorders. ${ }^{1-3}$ The only treatment for pheochromocytoma is resection, and the surgical approach depends on the tumor size. ${ }^{4}$

A 39-year-old woman with a history of 2 episodes of severe hypertension $(180 / 125 \mathrm{~mm} \mathrm{Hg})$ treated with captopril ( $25 \mathrm{mg}$ ) and bromazepam (3 mg) was admitted to the emergency department due to heart failure. The current episode was the second admission within 1 month, and the patient was investigated for secondary hypertension by her family physician.

On admission, the patient reported shortness of breath, heart palpitations, general weakness, headache, sweating, and nausea. She was diagnosed with pulmonary edema, and her blood pressure was $85 / 55 \mathrm{~mm} \mathrm{Hg}$. Moreover, supraventricular tachycardia (160 bpm) was noted, and oxygen saturation was $86 \%$. Laboratory findings on admission showed leukocytosis (white blood cell count, $\left.11.24 \times 10^{9} / \mathrm{l}\right)$ and lactic acidosis $(\mathrm{pH}, 7.238)$. The levels of troponin I were $817.4 \mathrm{ng} / \mathrm{l}$; lactate, $6.6 \mathrm{mmol} / 1$; and glucose, $17.9 \mathrm{mmol} / \mathrm{l}$.

Computed tomography showed a heterogeneously enhancing mass (size, $107 \times 93 \times 137 \mathrm{~mm}$ ) in the left adrenal gland (FIGURE 1A) as well as pectus excavatum (FIGURE $1 \mathrm{~B}$ ). Chest X-ray revealed pulmonary edema (FIGURE 1 C). The diagnosis was confirmed by serum levels of free metanephrine (2.092 nmol/1; reference range $<0.456 \mathrm{nmol} / \mathrm{l}$ ) and normetanephrine (1171 nmol/1; reference range $<1.037 \mathrm{nmol} / \mathrm{l}$ ), measured before hospitalization. Transthoracic echocardiography showed hypercontractility of the basal and apical walls as well as hypokinesia of mid-ventricular walls of the left ventricle with a reduced ejection fraction (35\%-40\%). The echocardiographic findings suggested Takotsubo cardiomyopathy (the inverted anatomic variant, also known as the "artichoke" heart; FIGURE 1D).

A multidisciplinary team decided on a surgical removal of the pheochromocytoma as soon as hemodynamic stability and full $\alpha$-blockade were achieved. Intensive care unit (ICU) treatment was started with infusions of norepinephrine $(0.15 \mu \mathrm{g} / \mathrm{kg} / \mathrm{min})$ and dopamine (5 $\mu \mathrm{g} / \mathrm{kg} / \mathrm{min})$. Then, an intra-aortic balloon was inserted, and urgent renal replacement therapy was commenced. The highest troponin I and N-terminal fragment of the prohormone brain natriuretic peptide (NT-proBNP) levels were noted on the second day: $15611.2 \mathrm{ng} / \mathrm{l}$ and $1746.7 \mathrm{ng} / \mathrm{l}$, respectively. The intra-aortic balloon was removed on day 9 of hospitalization. Phenoxybenzamine at an uptitrated dose of $20 \mathrm{mg}$ to $240 \mathrm{mg}$ was administered on a daily basis. After complete $\alpha$-blockade was achieved, labetalol infusion was titrated under close supervision at the ICU. Labetalol is not recommended for patients with pheochromocytoma because nonselective $\beta$-adrenergic blockers may cause severe hypertension. However, it was used in our patient, as selective 

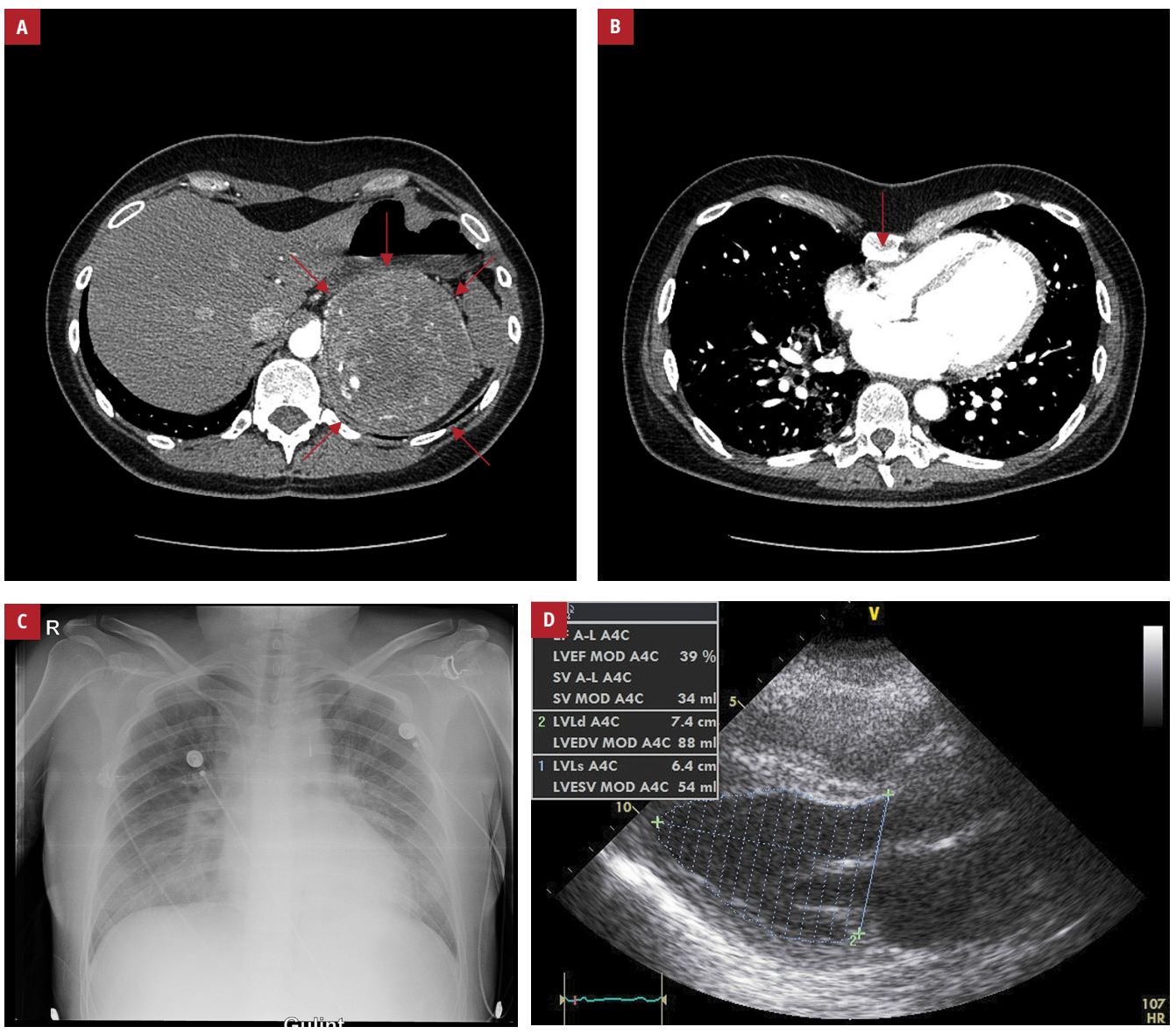

FIGURE 1 A - contrast-enhanced computed tomography scan showing a heterogenous left adrenal mass of $10 \mathrm{~cm}$ in diameter (arrows), an axial view; $\mathbf{B}$ - contrast-enhanced computed tomography scan showing the pectus excavatum (arrow); $\mathbf{C}$ - chest $\mathbf{X}$-ray showing pulmonary edema; D - transthoracic echocardiography demonstrating Takotsubo cardiomyopathy

$\beta_{1}$-adrenoreceptor blockers were unavailable. ${ }^{5}$ Regardless of the tumor size, left laparoscopic adrenalectomy was performed on day 17 of hospitalization, exactly after 10 days of phenoxybenzamine and labetalol treatment.

Initially, anesthesia was successful. Hemodynamic stability was achieved with noradrenaline $(0.02 \mu \mathrm{g} / \mathrm{kg} / \mathrm{min})$, until the rupture of a giant tumor and massive arterial bleeding occurred. Laparoscopy was immediately switched to laparoto$\mathrm{my}$, and thus the dose of vasopressors was dramatically increased. The total blood loss of $2.5 \mathrm{li}-$ ters lead to hemorrhagic shock, and transfusion of red blood cells $(1383 \mathrm{ml})$, fresh frozen plasma $(1037 \mathrm{ml})$, and platelets $(340 \mathrm{ml})$ was performed.

The postoperative period at the ICU was uneventful, and no vasoactive drugs were necessary. Prior to discharge, troponin I levels decreased to $105 \mathrm{ng} / \mathrm{l}$, and NT-proBNP, to $452 \mathrm{ng} / \mathrm{l}$. As cardiac dysfunction was unrelated to myocardial ischemia, the cardiac prognosis is good. ${ }^{4}$ Histologic examination confirmed the diagnosis of pheochromocytoma, which was $13 \mathrm{~cm}$ in diameter and $450 \mathrm{~g}$ in weight. The patient was discharged on day 22 of hospitalization after serum free metanephrine and normetanephrine levels had normalized.

\section{ARTICLE INFORMATION}

CONFLICT OF INTEREST None declared.

OPEN ACCESS This is an Open Access article distributed under the terms of the Creative Commons Attribution-NonCommercial-NoDerivatives 4.0 International License (CC BY-NC-ND 4.0), allowing third parties to download articles and share them with others, provided the original work is properly cited, not changed in any way, distributed under the same license, and used for noncommercial purposes only. For commercial use, please contact the journal office at kardiologiapolska@ptkardio.pl.

HoW To CITE Kontrimaviciute E, Valeviciene N, Motiejuniene AB, et al. Successful treatment of giant pheochromocytoma-induced Takotsubo syndrome with adrenalectomy. Kardiol Pol. 2020; 78: 249-250. doi:10.33963/KP.15122

\section{REFERENCES}

1 Johnson W, Nguyen ML, Patel R. Hypertension crisis in the emergency department. Cardiol Clin. 2012; 30: 533-543.

2 Łubińska M, Hoffmann M, Jendrzejewski J, et al. Successful surgical treatment of pheochromocytoma during pregnancy. Pol Arch Intern Med. 2018; 128: 322-323.

3 Lenders JW, Duh QY, Eisenhofer G, et al. Pheochromocytoma and paraganglioma: an endocrine society clinical practice guideline. J Clin Endocrinol Metab. 2014; 99: 1915-1942.

4 Gąsior ZT, Rożek B, Dąbek J, et al. Prognostic assessment of selected clinical and ultrasonographic indices in patients with non-critical lesions in coronary angiography Kardiol Pol. 2018; 76: 173-180.

5 Eisenhofer G, Rivers G, Rosas AL, et al. Adverse drug reactions in patients with phaeochromocytoma: incidence, prevention and management. Drug Saf. 2007; 30: 1031-1062 